\title{
HELOISA ODER DIE SEHNSUCHT NACH FREUNDSCHAFT $^{*}$
}

Ursula Niggli*

\section{RESÜMEE}

Unter dem Aspekt von Freundschaft wird die mehrmaligen Rollenwechsel einschließende Liaison zwischen Abaelard und Heloisa umrisshaft in ihrem Verlauf und ihrer Entwick-lung nachgezeichnet. Das Herzstück meiner Deutung thematisiert die Verführung Heloisas, ihre absolute (reine) Liebe und ihr Freundschaftsbegehren. Nicht weniger ausführlich gehe ich andererseits auf drei mögliche Gründe für Abaelards Unvermögen Heloisa gegenüber ein, und zwar in der Absicht, seine Liebe für Heloisa (entgegen dem Verdacht aller Welt) ganz in ihrem Sinn $\mathrm{zu}$ rechtfertigen.

SCHLÜSSELWÖRTER: Heloisas Autonomie. Freundschaft. Absolute (reine) Liebe. Paraklet. Askese.

\section{ABSTRACT}

From the cardinal motive of friendship I scrutinized the complex relationship between Abelard and Heloise in its development and various roles. The principal focus of research is on the one hand Heloise's seduction, her absolute (pure) love and her desire for Abelard's friendship. On the other hand I sought for reasons why

* Dieser artikel ist zuerst erschienen bei: APPUHN-RADTKE, Sibylle und WIPFLER, Esther p. (Hrsg.): Freundschaft. Motive und Bedeutungen. Veröffenthlichungen des Zentralinstituts für Kunstgeschichte, Bd. XIX, München, 2006.

** Leiterin des privaten Philosophie-Instituts "Paraklet" in Zürich. 


\begin{abstract}
Abelard was so utterly unable to understand Heloise and to react properly upon her wish. Thereby I try to justify Abelard's love for Heloise according to the hope she expressed herself (against the suspicion of everybody).
\end{abstract}

KEYWORDS: Heloisa's autonomy. Friendship. Total (pure) love. Paraclete. Asceticism.

Das Thema der Beziehung zwischen Heloisa und Abaelard blieb seit jeher brisant und aufwühlend. Im 17. Jahrhundert waren das Schicksal und die Briefe der angeblichen "libertine”, welche der freien Liebe vor der Ehe und namentlich einem Leben als Nonne den Vorzug gegeben haben soll, mehr oder weniger frei erfunden worden ${ }^{1}$, auch wenn der lateinische Briefwechsel für Gelehrte seit 1616 in der Edition der Schriften Peter Abaelards von F. d'Amboise und A. Duchesne vorlag. Trotz der eingehenden Artikel, die Pierre Bayle in seinem prominenten Dictionnaire historique et critique über Abaelard und Heloisa publiziert hatte ${ }^{2}$, verblaßte Heloisas Namen im 18. Jahrhundert zunehmend zu einer Chiffre für aufklärerische und früh-romantische Ideale oder wurde das Etikett für eine

1 In der Folge der vom CHEVALIER DE GUILLERARGUES abgefassten, aber lange Zeit für echt gehaltenen Lettres portugaises (Briefe einer portugiesischen Nonne von 1669) entstand 1687 die ganz dem galanten Zeitgeschmack adaptierte Phantasiefassung des Briefwechsels von ROGER DE BUSSY-RABUTIN, vgl. in: Les Lettres de Messire Roger de Rabutin, comte de Bussy, Paris 1697, 3 Teile in 4 Bänden, zweiter Teil S.116-151. Sie löste nebst dem Text von JACQUES ALLUIS: Les amours d'Abailard et d'Héloïse, Amsterdam 1695, eine Flut von Briefromanen und heroischen Briefgedichten über das angeblich frivol-tragische Melodram aus.

2 Erschienen in 3 Bänden, Amsterdam 1697; 1741 von JOHANN CHRISTOPH GOTTSCHED ins Deutsche übersetzt, 4 Bände; Bd.1, S.18-24: Abälard; Bd.2, S.758-763: Heloise.

3 JEAN JACQUES ROUSSEAU ging in seinem Briefroman: Lettres de deux amans, habitants d'une petite ville aux pieds des Alpes (Julie ou la Nouvelle Heloyse), Genf 1761 keineswegs vom Urtext, sondern von CHARLES-PIERRE COLARDEAU: Lettre amoureuse d'Hélö̈se à Abailard, Au Paraclet 1758, aus. Die Parallele zu den Originalpersonen besteht nur darin, daß Saint-Preux wie

Educ. e Filos., Uberlândia, v. 20, n. 40, p. 173-206, jul./dez. 2006. 
bestimmte Literaturgattung. ${ }^{3}$ Seitens kirchennaher Interpreten blieb man im Gegenzug darum besorgt, das Bild der vorbildlichen Nonne intakt $\mathrm{zu}$ erhalten, weshalb man ihre - angeblich unglaubwürdigen - Klagen über vergangene Liebesfreuden einem männlichen Fälscher ${ }^{4}$ oder sogar ihrem ehemaligen Liebhaber Abaelard selber ${ }^{5}$ in die Schuhe schob.

Abaelard seine junge Schülerin verführt. ROUSSEAU ersetzte Religion und Kloster durch Tugend und variierte POPEs Gedanken über das wahre Glück in Hingabe, Verzicht und Seelenfreundschaft (auch das Gedicht von ALEXANDER POPE: Eloïsa to Abelard, in: The works of Mr. Al. Pope, London 1717, Bd.1, S.413, entstand ohne Kenntnis der Originaltexte). Im 24. Brief des ersten Teils schreibt ROUSSEAU S.66: Quand les lettres d'Héloïse et d'Abelard [sic !] tomberent entre vos mains, vous savez ce que je vous dis de cette lecture et de la conduite du Théologien. J'ai toujours plaint Héloïse ; elle avoit un cœur fait pour aimer ; mais Abelard ne m'a jamais paru qu'un misérable digne de son sort, et connoissant aussi peu l'amour que la vertu. In der Entwicklung nach ROUSSEAU bedeutete, ,eine Heloise schreiben”, dann so viel wie einen Briefroman abfassen.

4 JOSEPH T. MUCKLE, der Editor der kritischen Ausgabe des Briefwechsels, erwartete, daß Abaelard Heloisa wegen "some of her impassioned and carnal outbursts" gescholten hätte. Er vermutete, daß ein unbekannter, genial begabter Redaktor die ersten beiden Briefe Heloisas [Brief 2 und 4], die einer allerseits verehrten Äbtissin nicht würdig seien, erweitert und umgeschrieben habe, vgl. Mediaeval Studies 15, 1953, S.59 und S.66f.

5 JOHN F. BENTON hielt Heloisas Briefe ursprünglich für das Werk eines Autors des 13. Jahrhunderts, der beabsichtigte, die Frauen als unterwürfige, sinnliche Wesen in ihre Schranken zu weisen; denn andere, wirklich von ihr stammende schriftliche Äußerungen bewiesen wie ihre Lebensleistung und das Zeugnis bewundernder Zeitgenossen: „Heloise must have been an outstanding person [...] we need not imagine her as so submissive or as so tortured by sensuality as she appears in the correspondence" (JOHN F. BENTON, in: Pierre Abélard, Pierre le Vénérable [Cluny 1972], Paris 1975, S.501). Später revidierte Benton seine These: Abaelard selber „began to fear that Heloise and the nuns needed male control from outside the convent, and he offered a new rule as the concluding letter of an exemplary correspondence which stressed his own role in the foundation of the convent and demonstrated the carnal weakness of a woman without proper male direction". BENTONS Schlußfolgerung: Heloisas Brief (Brief 6), in welchem sie unter anderem um eine Klosterregel bat, die sie nie befolgt habe, sei von Abaelard selber gefälscht worden (in: Petrus Abaelardus, ed. R.THOMAS, Trier 1980, S.51). 
Neuere feministische Forschung ${ }^{6}$ rügt zwar einige frauenfeindliche Äußerungen Heloisas, ist aber fasziniert von dem leidenschaftlichen ,Rosenkrieg', den Heloisa auch noch als Nonne gegen den einzig geliebten Mann ausfocht. In geradezu gotteslästerlicher Manier habe die Benediktinerin Abaelard ihrem göttlichen Herrn und Schöpfer vorgezogen, obwohl jener sie, bar eigener Schuldgefühle, in ihren eigenen Bedürfnissen (und namentlich in ihrem weiblichen Begehren!) unterdrückt und ihr mehrfach gröber Unrecht angetan habe. Die Repression Heloisas sei bei der Rezeption ihrer Briefe fortgesetzt worden, indem man die Stimme dieser hoch gebildeten Frau unter Vorspiegelung eines Fälschers im 13. Jahrhundert und durch die Legendenbildung ${ }^{7}$ späterer Zeiten zum Verstummen brachte.

Wenn man ihre eigenen Aussagen gelten läßt, stellt sich die Frage, inwiefern es diese Texte erlauben, derart in den ,Geschlechterkampf' moderner Zeiten einbezogen zu werden. Im Folgenden wird unter dem Blickwinkel von Freundschaft (vgl. Anm.30) die Beziehung zwischen Heloisa und Abaelard neu beleuchtet. ${ }^{8}$ Denn

6 Vgl. BARBARA NEWMAN: Authority, Authenticity, and the Repression of Heloise, in: Journal of Mediaeval and Renaissance (Early Modern) Studies vol.22, 1992, S.121-157 sowie die Anm.10.

7 CHARLOTTE CHARRIERs monumentale Darstellung: Héloïse dans l'histoire et la légende, Paris 1933, Slatkin Reprints, Genf 1977, ist hinsichtlich des Nachweises der Legendenbildung (S.365-572) und in ihrem Materialreichtum (mit insgesamt 618 bibliographischen Angaben, S.597-655) bisher unübertroffen. Der vorliegende Artikel erscheint in seinem ursprünglichen (dreifachen) Umfang in: Frühe Neuzeit. Festschrift für GÜNTER MÜHLPFORDT, ed. ERICH DONNERT, Bd.7, Köln 2007. Nebst durchgängigen Kürzungen entfielen in der vorliegenden Version die Kapitel zu Heloisas Lebensleistung und Abaelards Feminismus, ferner der ganze Kirchenvätersubtext und die Auseinandersetzung mit der Literatur in den Fußnoten.

8 Unter dem Titel: „Erotische Konfession und klösterliche Instruktion” gab ich im Sammelband: Peter Abaelard. Leben-Werk-Wirkung, Forschungen zur europäischen Geistesgeschichte Bd.4, ed. URSULA NIGGLI, Freiburg i.Br. 2003, S.91-113, einen gedrängten Überblick des Briefwechsels. Der vorliegende Artikel erscheint in seinem ursprünglichen (dreifachen) Umfang in: Frühe Neuzeit. Festschrift für GÜNTER MÜHLPFORDT, ed. ERICH DONNERT, Bd.7, Köln 2007. Nebst durchgängigen Kürzungen entfielen in der vorliegenden

Educ. e Filos., Uberlândia, v. 20, n. 40, p. 173-206, jul./dez. 2006. 
weshalb sollte nicht der Versuch unternommen werden, über die wenigen, aber umso heftiger debattierten Briefstellen hinausgehend, die ganze Geschichte, ihre Voraussetzungen und ihren zeitgenössischen Hintergrund (was die Genderfrage nicht ausschließt) wenigstens umrißhaft in seinem Verlauf und in seiner Entwicklung nachzuzeichnen?

Seit Etienne Gilsons magistraler Deutung von 1938 wurde viel über das ,Schweigen' Heloisas zu Beginn ihres berühmten dritten Briefes (insgesamt Brief 6) spekuliert. ${ }^{9}$ Man stellte zur Debatte, ob die Priorin des Paraklet bekehrt worden sei oder ob sie bloß vor der Autorität ihres Seelsorgers Abaelard kapituliert habe. ${ }^{10}$ Vielleicht wäre es hermeneutisch ergiebiger, auf die Ansprechweise und Tonlage $\mathrm{zu}$ achten, in denen Heloisa Abaelard wenige Jahre nach dem Briefwechsel ihre Problemata vortrug. Denn anders als das zwischen den Zeilen greifbare ,Schweigen' über ihren

Version die Kapitel zu Heloisas Lebensleistung und Abaelards Feminismus, ferner der ganze Kirchenvätersubtext und die Auseinandersetzung mit der Literatur in den Fußnoten.

9 Abweichende Zählung: Die deutsche Zählung folgt MIGNE (PL 178) und zählt die Historia Calamitatum (abgekürzt: H.C.) als Brief 1, während englische Publikationen in der Regel MUCKLE folgen, der die Autobiographie nicht zum Briefwechsel zählt (seine Edition der H.C. in: Mediaeval Studies 12, 1950). Zitierte lateinische Originaltexte: Im Folgenden wird die H.C. nach der kritischen Edition von JACQUES MONFRIN, 3. Aufl. Paris 1967, nach Seite und Zeile zitiert; der anschließende Briefwechsel mit Heloisa (Brief 2 bis 7) nach J.T. MUCKLE, in: Mediaeval Studies Bd.15, 1953, S.47-94 und Bd.17, 1955, S.240-281 und Abaelards Klosterregel (Brief 8) nach T.P. McLAUGHLIN, in: Mediaeval Studies Bd.18, 1956, S.241-292. Zitierte Übersetzungen: EBERHARD BROST (Ed.): Abaelard: Die Leidensgeschichte und der Briefwechsel mit Heloisa (1938), 4.verb. Auflage, Heidelberg 1979 [dtv, WBG]; HANS-WOLFGANG KRAUTZ (Ed.): Abaelard: Der Briefwechsel mit Heloisa (1989), erg.Ausg. Stuttgart 2001 [UniversalBibliothek; 3288]; BETTY RADICE (Ed.): The Letters of Abelard and Heloise (1974), Harmondsworth 1979 [Penguin Classics, Brief 7 nur knapp zusammengefaßt]. Wo bei der Übersetzung von Zitaten nichts vermerkt ist, stammt die Übersetzung von mir.

${ }^{10} \mathrm{Vgl}$. LINDA GEORGIANNA: “Any Corner of Heaven: Heloisas's Critique of Monasticism", in: Mediaeval Studies 49, 1987, S.224f. und 228f. sowie PEGGY KAMUF: Fictions of Feminine Desire: Disclosures of Heloise, Nebrasca 1982, S.8f. 
persönlichen Zwiespalt, das offen läßt, ob und wie sie den Konflikt betreffend ihre mangelnde klösterliche Berufung und die Anhänglichkeit ihrer ganzen Person an Abaelard verwinden konnte, ließe sich womöglich an ihren bibeltheologischen Anfragen das Maß ihrer persönlichen Freiheit und ihres wieder erlangten inneren Friedens ablesen.

Da das zwölfte Jahrhundert das goldene Zeitalter der amicitia war ${ }^{11}$, könnte sich das Freundschaftsideal ${ }^{12}$ als der unverfänglichere Raster für die (mehrmaligen Rollenwechsel einschließende) Ausgestaltung dieser Geheimnis umwitterten Liaison eignen. Verglichen mit den bisherigen Deutungsmustern, der "freien Liebe”, dem „religiösen Leben” und den "misogynen Schranken”, bietet dieses Erklärungsmodell den Vorteil der Unparteilichkeit: „Freundschaft” ist der Titel für eine aus freien Stücken gestaltete, streng symmetrische, beidseitig hohem Ethos, aber kaum Konventionen unterstehende Nahebeziehung, die sowohl weltliche und geistliche Partner als auch gleich- und gemischtgeschlechtliche Paare eingehen können.

Freundschaft ist ein Ideal, das bei Gleichheit und Freiheit eine aufrichtige und offenherzige Beziehung anstrebt. Wo Freundschaft zum Tragen kommt, ist im Prinzip die Dominanz des einen Partners auch dann eliminiert, wenn ihm nach gesellschaftlichem oder rezeptionsgeschichtlichem Urteil der Vorrang gebührte. Die Balance gegenseitiger Anerkennung und Liebe aufrechtzuerhalten, bleibt die Aufgabe zweier, je für sich um ihren Wert wissenden, verletzlichen und sich weiter entwickelnden Individuen. Es ist der hohe, das Selbst des anderen mitbegründende Wert echter Freundschaft, welcher zu dieser Verletzlichkeit der Freunde führt und den Verlust einer Freundschaft zu einer bitteren Erfahrung macht.

${ }^{11}$ Vgl. BRIAN PATRICK McGUIRE: Friendship and Community: The Monastic Experience 350-1250, Cistercian Studies Series no.95, Kalamazoo 1988, S.231ff. und S.296 (zu Aelred).

${ }^{12}$ Vgl. PLATO: Lysis; ARISTOTELES: Nikomachische Ethik VIIIf.; CICERO: Laelius de amicitia; Cassian: Collationes XVI; AELRED VON RIEVAULX: De spiritali amicitia. 
Ein Wink auf meine durchgängige These sei bereits vorweggenommen: Indem das Paar den Weg von einer stürmischen Liebe zu einer Freundschaft beschritt, gelang es Heloisa, sich von dem durch Alter und Bildung ursprünglich so überlegenen Mann zu emanzipieren. Umgekehrt streifte Abaelard unter dem maßgeblichen - emotionalen und gedanklichen - Einfluß seiner Heloisa die damaligen misogynen Vorurteile ab; dies befähigte ihn, nicht nur in Heloisa die ebenbürtige, ja überlegene "Schwester in Christo" wahrzunehmen, sondern in geradezu feministischer Aufgeschlossenheit über die verschiedenen Rollen von Frauen nachzudenken.

\section{Sozialisation und Voraussetzungen}

Abaelard war das älteste Kind des Ritters Berengar von Le Pallet bei Nantes, eines gebürtigen Poiteviners, und seiner Frau Luzia, einer Bretonin. Berengar zog sich bereits zwischen 1100 und 1102 in die Abtei von Saint-Serge et Saint-Bach bei Angers zurück. ${ }^{13}$ So wurde der 1079 geborene Abaelard in jungen Jahren der verantwortliche Mann in der Familie, auch wenn er wegen seiner Gelehrtenlaufbahn auf das Erstgeburtsrecht verzichtet hatte. ${ }^{14}$ Bei der Profeß seiner Mutter war er, zumal aus Gründen der Erbregelung, anwesend. ${ }^{15}$ Noch bevor er unter dem Eindruck dieses Ereignisses um 1113 in Laon sein Theologiestudium aufnahm, hatte er in Corbeil und Melun, danach auf dem Genovefaberg in Paris eigene Schulen gegründet. Überarbeitung und Krankheit (nach Werner Robl wahrscheinlich eine erst im Alter wieder akut gewordene Organtuberkulose ${ }^{16}$ ) zwangen ihn zwischenzeitlich $z u$ einem mehrjährigen Erholungsaufenthalt zuhause in Le Pallet.

${ }^{13}$ Vgl. WERNER ROBL, in: Peter Abaelard 2003 (Anm.8) S.75f.

${ }^{14}$ H.C., ed. MONFRIN S. 63 Z 23ff.; ed. BROST S.9; ed. KRAUTZ S.5; ed. RADICE S.58.

${ }^{15}$ H.C., ed. MONFRIN S.67 Z 155ff.; ed. BROST S.14; ed. KRAUTZS.10; ed. RADICE S.62.

${ }^{16}$ Vgl. NIGGLI, in: Peter Abaelard 2003 (Anm.8) S.9 Anm.14. 
Aus der Widmung seiner Dialectica an den Bruder Dagobert und dem Umstand, daß er die schwangere Heloisa in seine bretonische Heimat, entführte', wo der gemeinsame Sohn Astralabius geboren wurde und bei Abaelards Schwester Dionysia aufwachsen sollte, ist zu schließen, daß Abaelard zeitlebens zu seinen Geschwistern ein herzliches Verhältnis unterhielt.

Anders beschaffen war die Herkunft seiner Privatschülerin, Geliebten, (geheimen) Ehefrau, Nonne, Priorin, Äbtissin und geistlichen Schwester Heloisa: Ihr Vater ist unbekannt. Heloisas Mutter Hersendis von Champagne (gest. 1114/1116) lebte zur Zeit ihrer mutmaßlichen Schwangerschaft (um 1094/5) mit dem in seiner Lebensführung nicht unbestrittenen späteren Ordensgründer Robert von Arbrissel und seiner Schar in den Wäldern von Craon. Sie wurde bald die rechte Hand dieser schillernden Persönlichkeit und die Seele des neu gegründeten Doppelklosters von Fontevrault.

Sainte-Marie, der Benediktinerinnenkonvent von Argenteuil, im späten 7. Jahrhundert gegründet und bis auf Karl den Großen dem Kloster von Saint-Denis untertan, war ein reiches, nur Töchtern wohlhabender und einflußreicher Familien offen stehendes Kloster. Hier wuchs Heloisa ohne Eltern und Geschwister, aber mit bildungsmäßigen Privilegien auf. Es verwundert nicht, wenn sie sich früh extensiver Lektüre zuwandte. In der Bibliothek des Klosters von Sainte-Marie wird es nicht an Anregungen für ein neugieriges, mit rascher Auffassung begabtes Mädchen gefehlt haben, das die alten Sprachen Latein, Griechisch und Hebräisch lernte und seinen eigenen Horizont ständig erweiterte. Für eine Auseinandersetzung mit der Welt und mit Gleichaltrigen fand die Heranwachsende in den Klostermauern von Argenteuil wohl wenig Gelegenheit. Wie befreiend und ihr Bedürfnis nach Austausch befriedigend muß für Heloisa der Dialog mit Abaelard geworden sein!

Nachdem Heloisa bei ihrem Oheim Fulbert eingezogen war, genoß sie bald den Ruf einer puella docta. Der 38jährige, an der Kathedralschule von Notre-Dame lehrende, in Liebesdingen völlig unerfahrene Philosophie- und Theologieprofessor Abaelard verliebte sich von fern in die junge, anmutige Frau, die wegen ihrer 
Gelehrsamkeit in ganz Paris von sich reden machte. Auf seinen Wunsch nahm ihn der Chorherr Fulbert in sein Haus auf und vertraute ihm, sofern seine Vorlesungen ihm dafür Zeit ließen, seine Nichte als Privatschülerin an. Abaelards Plan, Heloisa zu seiner Geliebten zu machen, stand nichts mehr im Weg. Naiv und wegen Abaelards gutem Ruf bot Fulbert seine junge Nichte, "ein zartes Lamm einem heiß hungrigen Wolf", an, indem er Abaelard des Tages und der Nacht das Verfügungs- und Züchtigungsrecht über seine Schülerin einräumte. ${ }^{17}$ Ein wenig Geldgier und Geltungssucht mag ebenfalls im Spiel gewesen sein, als Fulbert derart ahnungslos den illustren jungen Professor bei sich einquartierte.

\section{Die Beziehung und ihre Folgen}

Unübertrefflich schildert Abaelard in seiner Historia Calamitatum (abgekürzt: H.C.) den bald eintretenden, gemeinsamen, Sinnentaumel': „Ich kann es jetzt wohl kurz machen: Der Hausgemeinschaft folgte die Herzensgemeinschaft! Während unserer Unterrichtsstunden hatten wir vollauf Zeit für unsere Liebe. [...] Die Bücher lagen offen da, Frage und Antwort drängten sich, wenn die Liebe das bevorzugte Thema war, und der Küsse waren mehr als der Sprüche. [...] In unserer Gier genossen wir jede Abstufung des Liebens, wir bereicherten unser Liebesspiel mit allen Reizen, welche die Erfinderlust ersonnen. Wir hatten diese Freuden bis dahin nicht gekostet und genossen sie nun unersättlich in glühender Hingabe, und kein Ekel wandelte uns an."18

Ausser sich vor Freude teilte die ungefähr zwanzigjährige Heloisa ihrem Lehrer und Liebhaber Monate später ihre Schwangerschaft mit. Die intellektuell frühreife, aber etwas weltfremde und sich ihrer Reize wohl kaum bewußte junge Frau lernte vermutlich erst in Le Pallet, wo sie ihren Sohn Astralabius

${ }^{17}$ Vgl. H.C., ed. MONFRIN S.72 Z 316-329; ed. BROST S.20; ed. KRAUTZ S.15; ed. RADICE S.67.

${ }^{18}$ Zitiert H.C., ed. BROST S.21; ed. MONFRIN S.72f. Z332-337. 342-346; ed. KRAUTZ S.16; ed. RADICE S.67f. 
gebar, das reale Leben und die Strapazen damaliger Ehefrauen, Mütter und Wirtschafterinnen kennen.

Der Briefwechsel, in welchem Heloisa und Abaelard ihre Liebe fünfzehn Jahre nach den Ereignissen reflektierten, erlaubt eine Analyse der unterschiedlichen Gefühle und Beweggründe, derentwegen sich die beiden Liebenden aufeinander einließen. Vorher sind noch die äußeren Ereignisse zu berichten, die zwischen dem Auffliegen der Affäre und der an Abaelard begangenen Untat seiner Verstümmelung stattfanden. ${ }^{19}$

Nachdem Fulbert Abaelard aus dem Haus geworfen hatte, zerquälte sich dieser mit Selbstvorwürfen über das Unglück, in das er Heloisa gestürzt hatte. Heloisa stand ihm darin nicht nach, wenn sie Verzweiflung darüber marterte, wie ihr Freund vor aller Welt seine Ehre als Kleriker und vertrauenswürdiger Lehrer eingebüßt hatte.

Abaelard floh des Nachts während Fulberts Abwesenheit mit seiner schwangeren, als Nonne verkleideten Freundin. Während der Monate vor und nach der Geburt von Astralabius, die Heloisa bei Abaelards Schwester in der Bretagne verbrachte, wurde Fulbert schier wahnsinnig. ${ }^{20}$ Abaelard kehrte wieder nach Paris zu seiner Lehrtätigkeit in Notre-Dame zurück, aber blieb auf der Hut: Ob Fulbert ihn aus Rache ermorden oder schwer mißhandeln lassen würde?

Er war sich seiner Schuld und seines Vertrauensbruches nur allzu bewußt. Ohne Absprache mit Heloisa leitete er deshalb Verhandlungen mit Fulbert ein. Demütig bat der Philosoph Heloisas Oheim um Verzeihung und kündigte an, sich der von ihm angesetzten Sühneleistung für sein Vergehen zu unterwerfen. Von Mann zu Mann wies er Fulbert auf die Urgewalt Amors hin und erinnerte an den herabziehenden Einfluß der Frau, der an den überragenden Helden der Geschichte seit dem Sündenfall zu

${ }^{19}$ Vgl. H.C., ed. MONFRIN S.74-81 Z 379-641; ed. BROST S.22-33; ed. KRAUTZ S.17-26; ed. RADICE S.68-77.

${ }^{20}$ Avunculus [...] quasi in insaniam conversus, vgl. H.C., ed. MONFRIN S.74 Z 400ff.; ed. BROST S.23; ed. KRAUTZ S.18; ed. RADICE S.69. 
beobachten sei. Die angebotene Genugtuung einer Eheschließung mit Heloisa ging über Fulberts Erwartungen hinaus. Abaelard handelte die Klausel aus, wonach ihre Ehe zur Bewahrung seines guten Rufs geheim gehalten werden müßte. ${ }^{21}$ Die Aussöhnung mit Fulberts Sippe wurde durch einen Friedenskuß besiegelt.

Abaelard reiste sogleich in seine Heimat, um seine Freundin zu holen und sie zu seiner Frau zu machen. Heloisa opponierte aufs Energischste gegen eine Ehe. Ihre Hauptargumente waren, eine Heirat bringe ihn persönlich in Gefahr und mache ihn unglücklich; denn Fulbert lasse sich nicht wirklich versöhnen. Überdies würden sie beide durch eine Ehe nur erniedrigt: Er werde als Knecht der Gattin der Wissenschaft und der Kirche abhanden kommen. Was aber könne sie gewinnen, wenn sie für ihn bloß zum Hemmschuh werde?

Nebst den wohl in der Bretagne gemachten Beobachtungen, wie es um Kleinkinder und ihre Bedürfnisse zu- und hergeht, falls deren Eltern nicht wohlhabend sind und sich keine weitläufige Wohnstätte mit Bediensteten leisten können, bietet sie ihre ganze Belesenheit auf, um Abaelard klar zu machen: Nicht nur der Apostel Paulus warnte vor der leiblichen Trübsal von Ehegatten. Auch die Kirchenväter - allen voran Hieronymus in seiner Streitschrift gegen Jovinian - und vormals schon die Propheten des Alten Testamentes und alle heidnischen Philosophen seien sich einig gewesen über die grundsätzliche Unvereinbarkeit einer Ehe mit einem der Wissenschaft und Weisheit geweihten Leben. Theologie und Philosophie verlangten nun einmal einen ganzen Menschen und ein in Abgeschiedenheit und Enthaltsamkeit gelebtes Leben. Das Opfer, das zu ihrer Zeit Mönche aus Gottesliebe brächten, hätten bereits die großen heidnischen Philosophen des Altertums der Weltweisheit dargebracht, wie Philosophie denn weniger auf Intellektualismus als auf ein Leben im Sinne der göttlichen Bestimmung ziele.

${ }^{21}$ Der Zölibat für Priester und höhere Geistliche war zwar damals noch nicht vorgeschrieben, aber unter dem Einfluß der Kirchenväter war ein asketischer Code für ein vorbildliches christliches Leben verbindlich; deshalb war eine Ehe auch für die Lehrtätigkeit an einer Kathedralschule nicht wünschenswert.

Educ. e Filos., Uberlândia, v. 20, n. 40, p. 173-206, jul./dez. 2006. 
Wenn er schon auf seinen geistlichen Ornat als Kleriker verzichten wolle, möge er wenigstens nicht auch gleich noch seinen Philosophenmantel wegwerfen, um in Unzüchtigkeit (obscenitates) und sündiger Lust (turpes voluptates) zu versinken. Was sie selber betreffe, sie gebe dem Namen "Freundin” (amica) den Vorzug vor "Gattin” (uxor): In frei schenkender Liebe, aber nicht durch das eheliche Band wolle sie ihm verbunden sein. Andernfalls werde bald die Bitterkeit kommenden Elends die Süße der verlorenen Liebe aufwiegen. Abaelard fügt bei: Unterdessen erkannte die ganze Welt, wie wahr Heloisas Beurteilung der Lage ${ }^{22}$ gewesen ist.

Deutlich wird, wie sich Heloisa in ihrer Abmahnung von einer Ehe am asketischen Code der Kirchenväter orientierte und Fulberts Unversöhnlichkeit und Geltungssucht voraussah. Doch Abaelard setzte sich durch. In Anwesenheit einiger weniger Verwandter als Trauzeugen fand in aller Heimlichkeit (im Morgengrauen nach einer durchbeteten Nacht) die Einsegnung ihrer Ehe statt. Danach sahen sich die beiden eher selten.

Trotz der zugesicherten Geheimhaltung prahlte Fulbert bald überall mit der Heirat seiner Nichte. Da Heloisa sie standhaft ableugnete, bekam sie das Mißfallen ihres Onkels tüchtig zu spüren (mit contumeliae können sowohl Prügel als Schmähungen gemeint sein). Deshalb brachte Abaelard sie ins Kloster von Argenteuil, wo sie aufgewachsen war, und ließ sie als Laienschwester einkleiden. Wie wir aus Brief 5 wissen, drängte er sie „aus gieriger Unbeherrschtheit" auch in Sainte-Marie in einem Winkel des Refektoriums zum Geschlechtsverkehr, und zwar entgegen ihrer ausdrücklichen Bitte, darauf $\mathrm{zu}$ verzichten. ${ }^{23}$

Fulbert und seine Sippe vermeinten, Abaelard habe sich Heloisas entledigen wollen und sie deshalb fortgebracht. Unter Beihilfe eines bestochenen Dieners überfielen ihn des Nachts zwei

\footnotetext{
${ }^{22}$ Vgl. H.C., ed. MONFRIN S.75-79, ed. BROST S.24-30, ed. KRAUTZ S.18-23 und ed. RADICE S.70-74.

${ }^{23}$ Ed. MUCKLE S.88; ed. BROST S.130f.; ed. KRAUTZ S.102; ed. RADICE S.146.
}

Educ. e Filos., Uberlândia, v. 20, n. 40, p. 173-206, jul./dez. 2006. 
Gedungene und beraubten ihn derjenigen Organe, mit denen er die Angehörigen Heloisas gekränkt hatte. Abaelard schreibt, das Wehgeschrei der Kleriker und Studenten habe ihn mehr geschmerzt als die Wunde, die ihm noch halb im Schlaf beigebracht worden sei. In dieser Schmach flüchtete sich Abaelard hinter die Mauern des angesehenen Königsklosters von Saint-Denis, aber nicht ohne vorher Heloisa zum Klostereintritt in Argenteuil gedrängt zu haben.

Weil der Verzicht auf den eigenen Willen um Abaelards (statt um Gottes willen) eine prominente Rolle in Heloisas Briefen spielt, ist hier kurz auf die eindrucksvolle Szene von Heloisas Profeß einzugehen. ${ }^{24}$ Bevor Heloisa entschlossen zum Altar schreitet und den vom Bischof geweihten Nonnenschleier in Empfang nimmt, zitiert sie unter Schluchzen Worte der Römerin Cornelia, die nach Selbstanklage und Aufopferung klingen. ${ }^{25}$ Ich vermute, daß sich die kluge Heloisa der weiblichen Subversivität dieses Zitates sehr wohl bewußt war.

${ }^{24}$ H.C., ed. MONFRIN S.81 Z 625-641; ed. BROST S.32f.; ed. KRAUTZ S.25f.; ed. RADICE S.76f.

25 “O, herrlicher Gatte, besseren Ehbetts wert! So wuchtig durfte das Schicksal treffen ein solches Haupt? Ach mußt' ich darum Dich freien, daß Dein Unstern ich würd? Doch nun empfange mein Opfer, freudig bring ich es Dir", zit. H.C., ed. KRAUTZ S.25f. Heloisas Zitat stammt aus: MARCUS ANNAEUS LUCANUS: Bellum civile [Pharsalia] VIII, 94-98 (ed. WILHELM EHLERS, Darmstadt 2.Aufl. 1978, S.352f.). In seinen Kontext bei Lucan gestellt, ergibt sich ein komplexeres Bild: Cornelia trifft ihren Gatten Pompejus nach dessen Niederlage gegen Caesar und beklagt ihn, woraufhin Pompejus sie tadelt: Er sei am Leben, und ihrem Geschlecht stünden politische Sorgen gar nicht an, sondern lediglich das persönliche Wohlergehen ihres Gatten, es sei denn, sie habe statt seiner bloß seinen Ruhm geliebt! Cornelia repliziert mit den von Heloisa zitierten Worten; sie ist ihrem Gatten überlegen, wenn sie subtil (unter Wahrung der demütigen weiblichen Form) sowohl die Rüge als auch das Mißtrauen ihres Gatten zurückweist: Mit dem Angebot, ihr Leben für ihn zu opfern, zerstreut sie des Pompejus Zweifel an der Beschaffenheit ihrer Liebe; denn würde sie das Seinige statt die Person ihres Gatten lieben, machte es keinen Sinn, dafür das eigene Leben hinzugeben. Zugleich meldet die stolze Römerin Widerspruch gegen die ihr als Frau zugedachte eingeschränkte Rolle an und beharrt auf ihrer Befugnis, mit Pompejus auch über seine politische Niederlage zu sprechen.

Educ. e Filos., Uberlândia, v. 20, n. 40, p. 173-206, jul./dez. 2006. 
Denn erstens trug sie damals, vgl. Brief $2^{26}$, schwer an Abaelards Mißtrauen, das dazu führte, daß sie vor ihm ins Kloster eintreten mußte. Wie Pompejus in Worten zeigte Abaelard in seinem Drängen zuerst zu einer $E^{2} e^{27}$, dann zur vorgezogenen Profeß Heloisas, daß er der Liebe seiner jugendfrischen Freundin nicht traute und befürchtete, sie werde sich womöglich in Liebe einem anderen Mann zuwenden. Das kränkte sie tief, ohne daß es sie hinderte, Abaelards Befehl nachzukommen und die Warnung wohlmeinender Freunde und Verwandten in den Wind zu schlagen. Wie Cornelia in Worten trat Heloisa in der Tat den Beweis ihrer Liebe an (vgl. Anm.44). Zum anderen hebt das Cornelia-Zitat wie die frühere Abmahnung von einer Ehe (S.6) die Freudigkeit des Opfers und die frei schenkende Liebe hervor. Und schließlich transportiert es einen eminent emanzipativen Gehalt: Der Briefwechsel zeigt, daß sich auch Heloisa die Art, wie sie an Abaelards Schicksal Anteil nahm, nicht vorschreiben ließ.

Wenn Abaelard die Klostereintrittszene schildert, scheint er (wie in der Folge seine Leser) vor allem ergriffen von Heloisas Tränen und ihrem Opfermut; die Paradoxie zwischen weiblichem Gehorsam und emanzipativem Gehalt ist ihm entgangen. Das wird spätestens dann klar, wenn er zu Ende von Brief 5 bedenkenlos an die Rüge des doppelt unterlegenen Pompejus gegenüber Cornelia erinnert. $^{28}$

Beide Frauen versicherten ihre Gatten zwar ihrer uneingeschränkten, ja opferbereiten Zuneigung, wiesen jedoch listig die ihnen angesonnene akzidentielle Rolle zurück und

${ }^{26}[. .$.$] prius me sacris vestibus et professione monastica quam te ipsum Deo mancipasti.$ In quo fateo uno minus te de me confidere vehementer dolui atque erubui, aus: ed. MUCKLE S.72. Vgl. ed. BROST S.85; ed. KRAUTZ S.68; ed. RADICE S.117.

${ }^{27}$ Erst nach Heloisas Selbstenthüllung (in Brief 4) gesteht ABAELARD in seiner Antwort das in der H.C. verheimlichte, eigentliche Motiv für seine Ehe mit Heloisa: [...] nos indissolubili lege sacramenti nuptialis invicem astrinxerat [Subjekt ist Gott], cum cuperem te mihi supra modum dilectam in perpetuum retinere, aus: ed. Muckle S.90. Ed. Brost S.135: „Ich gedachte, meine über alles Maß Geliebte für alle Zeit zu behalten"; ed. Krautz S.106; ed. Radice S.149.

${ }^{28}$ Ed. MUCKLE S.92; ed. BROST S.141; ed. KRAUTZ S.111; ed. RADICE S.153.

Educ. e Filos., Uberlândia, v. 20, n. 40, p. 173-206, jul./dez. 2006. 
beharrten darauf, ihren Männern als Personen eigenen Rechts gegenüberzutreten, weshalb es unzulässig wäre, von ihrer ,Selbstaufopferung' zu reden. Dieser Charakterzug, wonach Heloisa auf ihrer eigenen Autonomie beharrte und der sie als selbständig denkende und eigenständige Persönlichkeit ausweist, wird sich anhand weiterer Zeugnisse mühelos belegen lassen. ${ }^{29}$

Im Eingehen auf die äußeren Ereignisse zeigte sich, wie sehr Abaelard bemüht war, die einzelnen Vorfälle, z.B. die Fulbert unterbreitete Bitte um Aussöhnung (vgl.S.5), getreu und prägnant zu erinnern. Bei Unschmeichelhaftem und Widersprüchlichem wäre am ehesten eine nachträgliche Glättung zu erwarten. Andererseits wird sich gerade eine literarische Verarbeitung aufwühlender Erlebnisse bemühen, den Geschehensablauf zu strukturieren und zu seiner Klärung auf tatsächliche oder bloß unterlegte Motive der Handelnden zurück zu greifen. Literatur dürfte die Bewußtheit des vergangenen Lebens also eher erhöhen und sich besonders der ideellen Ebene der Absichten und Gesinnungen der Protagonisten annehmen.

Um diese inneren Handlungsgründe geht es im Folgenden. In rückhaltloser Offenheit und mit dem Willen, sich selber und einander zu erforschen, haben Heloisa und Abaelard ihren ,Rosenstreit' ausgetragen. Das berechtigt zur Erwartung, beim aufmerksamen Zuhören und Achten auf ihre wechselseitigen Bezugnahmen ihren Motiven auf die Spur zu kommen. ${ }^{30}$

${ }^{29}$ In der Fälschungshypothese BENTONS (vgl. Anm.5) war zwar von Heloisas Unterwürfigkeit die Rede, sie findet aber an der geschichtlichen Gestalt keinen Anhalt, vgl. S.15f. und 17f. sowie im Kap. 7 der Originalfassung des vorliegenden Artikels (vgl. Anm.8).

${ }^{30}$ Es folgt jetzt das Herzstück meiner Darlegung, das leider (unter Wegfall von Zwischentiteln) ebenfalls stark gekürzt werden mußte (vgl. Anm.8). Um die Lektüre zu erleichtern, möchte ich wenigstens die vier von mir heraus gestellten Motive angeben: die Verführung S.8; die absolute (reine) Liebe S.9; das Freundschaftsbegehren S.11 und Abaelards Unverständnis und die möglichen Gründe dafür S.12. Das kardinale Motiv, in dem sich das Tor zur Deutung des von Heloisa inaugurierten Briefwechsels dreht und öffnet (lat. cardo meint Türangel), ist nach Titel und These dieses Essays Heloisas ,Freundschaftswunsch'. 


\section{Die Reflexion ihrer Beziehung}

In seiner Autobiographie schreibt Abaelard, wie ihn die Liebe $\mathrm{zu}$ der jungen Frau durchglühte (in amorem totus inflammatus), welche mit ihrer anmutigen Erscheinung und ihrer überragenden Gelehrsamkeit die Bewunderung und Zuneigung von ganz Paris auf sich gezogen hatte. ${ }^{31}$

Der entscheidende Satz nun, mit dem Abaelard seine Verführungsabsicht ausdrückte, lautet: Hanc igitur [...] censui in amorem mihi copulare, et me id facillime credidi posse (H.C., ed. Monfrin S.71 Z 288ff.). Radice (S.66) übersetzte: „I [considered all the usual attractions for a lover and] decided she was the one to bring to my bed, confident that I should have an easy success." Offenbar verleitete das lateinische Verb copulare zu dieser banalisierenden Übersetzung. Abaelard verwendet den Ausdruck häufiger. ${ }^{32}$ Danach drückt copulatio eine innige, geistig-seelische (auf die Herzen und Gott bezogene) Verbundenheit aus und ist mitnichten wie in den modernen Sprachen (engl. to copulate, copulation; franz. la copulation) der Terminus für Beischlaf. Schon Horaz, aber auch nachklassisch verbürgt ist copula als ,Liebesband' und ,Band der Freundschaft'. Deshalb verdient hier die literarische Übersetzung von Brost (S.19) den Vorzug: „Darum gedachte ich sie in Liebesbande zu verstricken, und am Gelingen zweifelte ich keinen Augenblick".

Freilich schreibt Brost (S.20) im Kontext, aber entgegen dem Original ( $Z$ 302f.: facilius ad consensum trahere) von Abaelards Absicht, "sie ganz bequem gefügig zu machen" bzw. sie zu "zähmen”, Krautz (S.15): „sie leichter zur Hingabe zu verleiten”, während Radice (S.66f.) mit Zurückhaltung und elegant formuliert:

${ }^{31}$ H.C., ed. MONFRIN S.71 Z 284-288: Que cum per faciem non esset infima, per habundantiam litterarum erat suprema $[. .$.$] et in toto regno nominatissimam fecerat.$

${ }^{32} \mathrm{Vgl}$. H.C., ed. MONFRIN S.74f. Z 386: copulatio animarum, Z 420: matrimonio copulando und Brief 3, ed. MUCKLE S.74 Z 4 v.u. (von der klugen Abigajil nach 1 Sam 25): mulier [...] nec ex sanctae devotionis professione Domino copulata und Brief 5, ed. MUCKLE S.92 Z 5 (von Heloisa als Braut Christi): quae te huic sponso felici copulasti matrimonio. 
",and so more easily winning her over". Heloisa wird gegen Ende von Brief 2 (ed. Muckle S.72) den Ausdruck trahere aufnehmen, wenn sie festhält: non religionis devotio sed tua tantum pertraxit iussio, wiederum exzellent (und mit der oben genannten Z 302f. der H.C. harmonierend) übersetzt von Radice (S.116): „It was not any sense of vocation which brought me as a young girl to accept the austerities of the cloister, but your bidding alone", während Brost (S.85) ,orientalisierend' übersetzt: "nein, Dein Wille allein stieß mich ins Kloster" und Krautz (S.67) wörtlich: "dein Befehl allein hat mich in blühender Jugend zur Düsternis des Klosterlebens hingezogen".

In zwei prägnanten, aber nicht anstößigen Wendungen hielt Abaelard in aller Offenherzigkeit seine damalige Absicht (als über beide Ohren in Heloisa Verliebter) fest, die Liebe dieser anziehenden jungen Frau für sich zu gewinnen. $\mathrm{Ob}$ er uns dabei sympathisch wird oder nicht, hängt aber - exempla docent wesentlicher von der modernsprachlichen Übersetzung als von Abaelards eigener dichter Diktion ab. Es fragt sich, ob Heloisas Ausdrucksweise ebenso offen ist für deutende Übersetzungen, obwohl sie nicht wie Abaelard "das erste menschliche Gefühl des nicht reflektierenden Betrachters gegen sich hat". ${ }^{33}$

Heloisa konnte Abaelards autobiographischen, an einen Freund gerichteten Leidensbericht (H.C.), der diesen Unbekannten über eigenes Unglück trösten wollte, nicht trockenen Auges lesen. Sie schreibt von ihrer beklemmenden Angst, daß ihr bald schon Unglücksboten den gewaltsamen Tod des von Feinden umstellten Liebsten (dilectissimus) meldeten. Aber, fährt sie fort, weder dieser befreundete Studienkamerad noch die aufrührerischen Mönche in St.Gildas de Rhuys in der Bretagne, denen Abaelard seit Verlassen des Paraklet um 1127 als Abt vorstand, hätten Abaelards Zuwendung verdient; nur seine getreuen Nonnen in seiner Eigengründung Paraklet und $\mathrm{zu}$ allererst sie, seine ihm ehemals durch das unauflösliche Band der Ehe Angetraute, besäßen Anspruch auf seine Unterstützung in Wort und Tat; denn wie niemand sonst nähmen sie Anteil an seinem schweren Schicksal.

${ }^{33}$ Vgl. das Nachwort von 1938, ed. BROST S.427. 
Deshalb möge er sie bald besuchen, ihnen persönlich durch Predigt und seelsorgerlichen Rat beistehen oder ihnen zumindest durch Briefe an seinem Leben Anteil geben.

Die Hauptklage in Heloisas Bittbrief bezieht sich allerdings auf die Vergangenheit und die langen Jahre seit ihrer beider Klostereintritt ${ }^{34}$, in denen Abaelard keinen Versuch unternommen habe, sie, die innerlich Schwankende, ohne Berufung ins Kloster Eingetretene und sich im Trennungsschmerz um ihren Geliebten Verzehrende, in seelsorgerlichem und freundschaftlichem Gespräch aufzurichten. Müßte er nicht wenigstens jetzt Gottes Liebe in ihr wecken wollen, mit schönerem Recht als vordem der Menschen Wollust?

Ihren Vorwurf, wonach er sie sträflich vernachlässigt habe, kann sie anknüpfen an seine Theorie gebliebenen Ausführungen über die Fürsorgepflicht an frommen, auf sich selbst gestellten Frauen respektive an seine Lehre vom unverkrampften Umgang, den (im Vollbesitz ihrer Männlichkeit) schon die alten Propheten, dann Jesus selber, seine Apostel und die von ihnen eingesetzten sieben Diakone und später die Kirchenväter und namentlich sein Alter Ego Hieronymus ${ }^{35}$ mit Gott geweihten Frauen pflegten.

${ }^{34}$ De facto sind gut fünfzehn Jahre seither vergangen: Klostereintritt beider um 1117; Datierung der Briefe zwischen 1132-1135. In der Literatur wurde weithin übersehen (aber nicht von Abaelard, vgl. Brief 5, ed. MUCKLE S.87, ed. BROST S.128, ed. KRAUTZ S.101 und ed. RADICE S.145), daß sich Heloisas Klage vornehmlich auf die Zeit unmittelbar nach dem Klostereintritt (conversio) bezieht, vgl. Brief 2, ed. MUCKLE S.70: iam dudum movit (Perfekt!); auch der Hinweis auf das foedus nuptialis sacramenti passte sonst schlecht; vgl. dieselbe Formulierung und Klage S.72 über Mitte. Bei BROST S.79 und KRAUTZ S.63 wird die Stelle ed. MUCKLE S.70: nostrae tenera conversationis (besser Variante T: conversionis) initia irrtümlich auf die Kooperation im Paraklet statt auf den ehemaligen Klostereintritt bezogen, bei BROST mittels eines erläuternden Einschubs.

${ }^{35}$ In Brief 7 schreibt Abaelard über diesen Kirchenvater des vierten Jahrhunderts:"Für den heiligen Mann war es eine herzerquickende Aufgabe, das schwache Geschlecht mit all seinen seelsorgerlichen Fähigkeiten auf dem steilen Tugendpfad vorwärts zu bringen." Ed. MUCKLE S.280, ed. BROST S.239 und ed. KRAUTZ S.193f. (bei RADICE ist dieser Brief nur kurz zusammengefaßt). Vgl. auch NIGGLI, Peter Abaelard 2003 (Anm.8) S. 356f. und 359f. zur Pointe der Deutung von Abaelards Autobiographie und seiner Identifikation mit Hieronymus.

Educ. e Filos., Uberlândia, v. 20, n. 40, p. 173-206, jul./dez. 2006. 
Im Kontext dieser mit emotionaler Wucht vorgetragenen Klage in Brief 2 über lange Jahre seiner Pflichtvergessenheit, die er wenigstens jetzt durch Besuche in seiner Eigengründung Paraklet oder zumindest Briefe an seine Herzliebste wieder gutmachen sollte, schreibt Heloisa von ihren Verdiensten und Opfern für Abaelard: Alle Welt bezeuge, daß ihre Liebe für ihn kein Maß gekannt habe (te semper, ut omnibus patet, immoderato amore complexa sum, ed. Muckle S.70). In jammervollem Schicksalsschlag habe der ruchbare Verrat, sie spielt auf Abaelards Kastration an, dazu geführt, daß sie ihn und mit ihm sich selbst verloren habe, wobei der Schmerz über die Art des Verlustes unvergleichlich viel größer sei als über den Schaden als solchen (incomparabiliter maior sit dolor ex amissionis modo quam ex damno, ebd. S.70).

Es überrascht, daß keine der drei Übersetzungen den von Heloisa intendierten Sachverhalt deutlich herausstellte ${ }^{36}$ : Heloisa gesteht, unter einer "Art von Verlust” (amissionis modus) zu leiden, der ihren Schmerz über die körperliche Versehrtheit (damnum) ihres Geliebten bei weitem überwiege, nämlich, so ist beizufügen, unter dem seither erfolgten totalen Verlust seiner persönlichen Zuwendung und Freundschaft. Denn sie habe in ihm je nur ihn selbst, nicht das Seine oder etwas von oder an ihm gesucht. Jedem Befehl von ihm (zuerst zur Eheschließung und zu ihrer Geheimhaltung, dann zum Klostereintritt) habe sie entsprochen. Ihre Liebe war geleitet vom Willen, bei ihm keinen Anstoß zu erregen $^{37}$ und sein vollumfängliches Wohlwollen, seine

${ }^{36}$ Ed. BROST S.80: „doch abgrundtief schmerzt es, wie ich Dich verlieren mußte”; ed. KRAUTZ S.63f.: „und daß mir aus der Art und Weise des Verlustes ein unvergleichlich viel größerer Schmerz erwächst als aus dem Unglück selbst"; ed. RADICE S.113: „and how my sorrow for my loss is nothing compared with what I feel for the manner in which I lost you". Besonders die englische Übersetzung scheint eine ,Umwertung' des von Heloisa verhüllt Angedeuteten vorzunehmen; danach wäre Abaelards Beeinträchtigung als Mann das große Unglück, so daß Heloisa ihren eigenen folgenden Ausführungen widerspräche (wie auch Abaelards eigenem Urteil über die Rettung seiner Seele, vgl. S.15).

${ }^{37}$ Vgl. H.C., ed. MONFRIN Z 553: nec me sustineret offendere respektive Brief 2, ed. MUCKLE S.70 Z 7 von unten: cum te in aliquot offendere non possem. 
Erkenntlichkeit und Dankbarkeit (alles im Wort gratia ausgedrückt ${ }^{38}$ ) $\mathrm{zu}$ gewinnen.

Deshalb habe ihre Liebe in Wahnsinn umgeschlagen, als sie sich durch ihre Profeß das Ziel ihrer Sehnsucht ohne Hoffnung, es wieder zu gewinnen, selbst entzog. Aber nur so konnte sie zeigen: Abaelard war der alleinige Eigentümer sowohl ihres Körpers als ihres Geistes. Gott wisse es: Niemals hätte sie etwas anderes als ihn, Abaelard, gesucht, ihn, nicht das Seinige habe sie in Reinheit begehrt (Nihil umquam, Deus scit, in te nisi te requisivi, te pure non tua concupiscens, ebd. S.70), mithin weder die Ehe noch eine Mitgift, aber auch nicht ihren Willen und ihre Lust.

Das Ende bezeuge unwiderleglich die Beschaffenheit ihrer Liebe von Anfang an. Denn solange sie fleischlich mit ihm verkehrt und die Liebeslust genossen habe (dum tecum carnali fruerer voluptate, S.73), bestand in den Augen der Welt die Ungewißheit, ob sie sich aus wirklicher Liebe oder bloß aus Begehrlichkeit dazu bereit gefunden habe (utrum id amore vel libidine agerem). Endlich habe sie sich alle Lüste dieser Welt versagt, um seinem Willen nachzugeben. Nur das eine behalte sie sich vor: Auf diese Weise nunmehr vorzüglich die Seine zu werden (Nihil mihi reservavi nisi sic tuam nunc praecipue fieri, ebenda). Dies sei unbestreitbar ihre Leistung, und was sie von ihm erwarte, sei für ihn eine Kleinigkeit; er möge es sich zu Herzen nehmen!

\section{Das Freundschaftsbegehren}

Heloisa schreibt in ihren beiden Briefen 2 und 4 nirgendwo: „Wessen ich zu meiner Seele Heil so dringend bedurft hätte und bedarf, ist Deine Freundschaft!" Und doch liegt dieser von mir in Anlehnung an die Freundschaftsdefinition des Isidor von Sevilla ${ }^{39}$

${ }^{38}$ Vgl. H.C., ed. MONFRIN Z 547f.: ut me ei sola gratia conservaret und Brief 2, ed. MUCKLE S.71,5: ut [...] ampliorem apud te consequerer gratiam und S.73,3f.: Bene autem tecum fuerit (Subjekt ist ihr Herz), si te propitium invenerit, si gratiam referas pro gratia, modica pro magnis, verba pro rebus.

${ }^{39}$ Vgl. ISIDORUS HISPALENSIS: Etymologiae X,4, in: PL 82,367: Amicus per derivationem quasi animi custos [dictus est]. Nach dieser Ableitung wäre ein Freund ein "Wächter über die Seele". 
formulierte Satz in lautem Schweigen unter all dem, was sie schreibt. Denn in gelebter Freundschaft bestünde die von ihr als uneingelöst beklagte Verpflichtung Abaelards den Nonnen und vor allem ihr selbst gegenüber.

Inwiefern bringt Brief 2 Freundschaftssachen zur Sprache? Mit brennendem Eifer habe sie die H.C. zu lesen angefangen, um sich durch deren Worte am Bildnis dessen, den sie real verlor, zu erquicken. Nach einer Zusammenfassung von Abaelards Leiden folgt ihr Begehren, in Zukunft nicht bloß durch Zufall eine an andere gerichtete Nachricht von ihm zu erhalten. Dann zitiert sie Seneca an Lucilius: „Niemals empfange ich einen Brief von Dir ohne das unmittelbare Gefühl, wir seien beisammen" (Numquam epistolam tuam accipio quin protinus una simus, ed. Muckle S.69). Nach Seneca frischten die Bilder abwesender Freunde zwar die Erinnerung auf, seien aber ein leerer Trost. Um wie viel erfreulicher seien dagegen Briefe, in denen die Eigenart des Freundes gegenwärtig werde!

Dem befreundeten Studienkameraden habe er seinen guten Willen gezeigt und das, was in freundschaftlicher Verbundenheit geschuldet sei (tam amicitiae quam societatis debitum), eingelöst, aber ihnen gegenüber, seinen engsten Freundinnen (amicissimae), Töchtern oder mit süßerem und heiligerem Namen zu Benennenden, habe er eine weit dringlichere Verpflichtung versäumt, zumal da die zarte Pflanzstätte des Paraklet seine eigene Schöpfung sei und für eine feste Einwurzelung des persönlichen Zuspruchs sowie seiner Predigt und Lehre bedürfe. Aber um ihre Schwestern beiseite zu lassen, möge er jetzt endlich seine bisher vernachlässigte Pflicht ihr gegenüber, seiner Einziggeliebten (unica tua), nachkommen. Denn er allein sei die Ursache ihrer nachhaltigen Betrübnis, deshalb vermöge nur er allein sie aufzurichten und $\mathrm{zu}$ trösten.

Besonders Heloisas Klage, daß sie mit ihm auch ihr Selbst verloren habe ${ }^{40}$, weist auf den beträchtlichen Anteil von

${ }^{40}$ Brief 2, ed. MUCKLE S.70: Nosti carissime, noverunt omnes quanta in te amiserim et quam miserabili casu summa et ubique nota proditio me ipsam quoque mihi tecum abstulerit und Brief 4, ed. MUCKLE S.78: Quid autemte amisso sperandum mihi 
Freundschaft an ihrer Liebe für Abaelard hin. Weil sie das Übermaß ihrer Liebe für Abaelard erkennt und es auch in einer seltenen geistigen Klarheit artikulieren kann, hielte ich es für abwegig, Heloisas Fixierung auf Abaelard zu pathologisieren; denn in einem solchen Fall fehlte nicht nur diese Artikulationsfähigkeit, sondern auch das Interesse an der Freiheit in der Beziehung. Für eine qualifizierte Freundschaft bleibt indessen das Element der Freiheit und Freiwilligkeit konstitutiv.

Weil für Heloisa die Freiheit und die frei schenkende Liebe ihres Freundes so wichtig waren, wirkte das Mißtrauen in seinem Wunsch, sie möge vor ihm ins Kloster eintreten, so verstörend auf sie (vgl. Anm.26). Und sie kann deshalb noch Jahre später nicht verstehen, warum er sich ihr seit ihrer beider Klostereintritt (conversio) trotz der unterdessen erfolgten Übergabe des Paraklet an die vertriebenen Nonnen und dem Dienst an ihnen persönlich so vollständig entzogen hat. Sie bittet ihn, ihr Verhalten, durch die Wirkung auf ihn ,voll schuldig' und zugleich ,voll unschuldig' hinsichtlich des entscheidenden Kriteriums: ihrer Gesinnung und Liebe für ihn, zu prüfen.

Umgekehrt fordert sie ihn heraus, seinerseits Rechenschaft abzulegen: Warum nur blieb er ihr über all die Jahre eine persönliche Aussprache schuldig? Sie führt ihren und den Argwohn aller darüber an, was ihn zu ihr hingetrieben habe: War es wohl eher Begierlichkeit als Freundschaft, die Glut der Leidenschaft statt echte Liebe? (Concupiscentia te mihi potius quam amicitia sociavit, libidinis ardor potius quam amor? S.72) Und sobald dieses Begehren gewichen sei, habe sich auch all das in nichts aufgelöst, was er ihr um dessentwillen an Wohlwollen, Freundschaft und Huld erwiesen habe. ${ }^{41}$

superest? Aut quae in hac peregrinatione causa remanendi [...] cui nec praesentia tua concessum est frui ut quandoque mihi reddi valeam? Ed. BROST S.80 und 103, ed. KRAUTZ S.63 und 81 sowie ed. RADICE S.113 und 129.

${ }^{41}$ Ed. MUCKLE S.72: Ubi igitur quod desiderabas cessavit quicquid propter hoc exhibebas pariter evanuit. Heloisas Satz schwieg sich über das Objekt des exhibere aus; ich fügte drei mögliche Übersetzungen für den Zentralbegriff gratia ein, worin Heloisa ihre Hoffnung zusammenfaßte, vgl. S.10, Anm.38: sola gratia und S.13f. 
Abaelards rhetorisch glänzende (um nicht zu sagen: galante) Antwort auf Heloisas Bittbrief erschüttert in seiner menschlichen Unzulänglichkeit. Er habe ihr nicht gegeben, worum sie bitte: Die Tatsache bestreite er nicht, aber ihre Deutung. Nicht Gleichgültigkeit (negligentia) habe ihn schweigen lassen, sondern das Vertrauen auf ihre Klugheit.

Wie schon in der H.C. ${ }^{42}$ zeichnet er im Brief 3 das Idealbild der Äbtissin Heloisa, die seiner Briefe und Anleitung gar nicht bedurft und schon als Priorin in Argenteuil ihre außergewöhnlichen Fähigkeiten bewiesen habe. ${ }^{43}$ Aber wenn sie in ihrer Bescheidenheit (humilitas) anders denke, möge sie ihm ihre religiösen Fragen schreiben, damit er sie mit Gottes Hilfe beantworte (hier setzen dann Brief 6 mit Heloisas Doppelanfrage, vgl. Anm.66, und in deren Fortsetzung die Problemata Heloissae ein).

Die ungefähr 38jährige Heloisa, die so dringend der seelischen Unterstützung eines einfühlsamen Freundes bedürfte, wird von ihm an den Gott der Barmherzigkeit gewiesen, bei dem sie und ihre Nonnen mit ihrer Fürsprache viel ausrichten könnten. Gerade das Gebet von Freunden und Gerechten stimme sogar den zürnenden Gott milde, aber wie viel mehr das Gebet

42 „Der Herr schenkte dieser meiner Schwester, der Leiterin des ganzen Konvents, daß sie besondere Gnade vor aller Augen fand: Die Bischöfe liebten sie gleich einer Tochter, die Äbte wie eine Schwester und die Laien wie eine Mutter. Jeder pries, der Bewunderung voll, ihre Frömmigkeit und Klugheit und die unvergleichliche Geduld und Sanftmut, die sie in allen Verhältnissen bewies. Sie zeigte sich nur sehr selten in der Öffentlichkeit, weil sie im stillen Kämmerlein unabgelenkt beten und meditieren mochte; um so stärker drängte es die Leute in der Welt, sie sehen und ihre geistlichen Tröstungen empfangen zu dürfen." Zitiert ed. BROST S.60f., vgl. ed. MONFRIN S.101 Z 1331-1340. Ed. KRAUTZ S.48 und ed. RADICE S.97.

43 „Wenn Gottes Gnade einer Frau im reichsten Maße alles geschenkt hat, was not tut, so durfte ich annehmen, sie brauche meine Briefe nicht. Und Du bist doch die Frau, die in Wort und Werk die Irrenden lehrt, die Kleinmütigen tröstet, die Schwachen aufrichtet; das ist bei Dir kein neues Können [...]. Wenn Du jetzt die gleiche liebevolle Sorgfalt für Deine Töchter hast, die Du ehemals für Deine Schwestern hattest, so ist das meines Erachtens genug [...]", zitiert ed. BROST S.89, vgl. ed. MUCKLES.73, ed. KRAUTZS.70 und ed. RADICE S.119. 
gottesfürchtiger Frauen. Die Totenerweckungen des Alten und Neuen Testamentes seien vornehmlich Frauen zugute gekommen; daher könne das Gebet ihrer hoch heiligen Gemeinschaft, in welcher so viele fromme Jungfrauen und Witwen unablässig dem Herrn dienten, leicht bei Gott die Erhaltung seines Lebens erreichen.

Auf Heloisas Bitte um persönliche Zuwendung repliziert Abaelard also mit der Gegenbitte, daß sie und ihre Nonnen bei Gott Fürbitte für ihn einlegen möchten. Denn ihre Frömmigkeit vermöge bei Gott viel und sie schulde, was sie zu leisten vermöchte, vorzüglich ihm. Derart kehrt Abaelard die Ausführungen Heloisas zu seiner so lange versäumten Pflicht schlicht um. Sie erhoffte sich Dankbarkeit und Erkenntlichkeit für ihren Freundschaftsbeweis ${ }^{44}$, wird aber in einer allgemeinen Überhöhung der Leistungsfähigkeit frommer Frauen mit neuen Ansprüchen an ihre Person konfrontiert, indem ihre bescheidenen, aber nicht minder lebenswichtigen Ansprüche wie bisher übersehen werden. Je größer die Hilfsbereitschaft und deren Erfolg für andere, desto geringer müße die eigene Hilfsbedürftigkeit sein, so Abaelards impliziter Trugschluß.

Die aufgestauten Gefühle, mit denen Heloisa Abaelard konfrontierte, mochten ihn zur Vorsicht mahnen und vielleicht sogar einschüchtern. Schon der römische Dichter Lukrez, den sie

${ }^{44}$ Vgl. zu Heloisas Profeß S.7, dann zu ihrer Reflexion darauf S.10. Nach dem letzten Zitat in Anm.38 war sie sich ihres zuvorkommenden Handelns bewußt (res, nicht bloß verba). In ihrer Belesenheit konnte ihr neben dem Jesus-Wort in Joh 15,13 sicher auch der klassische, bei CICERO (Tusc.disp.V,22,63) und HIERONYMUS überlieferte Freundschaftsbeweis nicht unbekannt sein: Der Pythagoreer Phintias wurde vom Tyrannen Dionysius I. ungerecht eines Mordanschlags beschuldigt und zum Tod verurteilt. Sein Freund Damon bürgte für ihn und kam fast ums Leben, weil Phintias zu spät auf dem Richtplatz erschien. Der Tyrann war von ihrer Freundestreue so beeindruckt, daß er beide am Leben ließ und darum bat, in ihren Freundschaftsbund aufgenommen zu werden. FRIEDRICH SCHILLER legte seiner Ballade: Die Bürgschaft die Fassung dieser Geschichte aus den Gesta Romanorum zugrunde, vgl. ELISABETH FRENZEL: Motive der Weltliteratur, Stuttgart 1976, S.196-201. 
seinerzeit in Fulberts Haus zusammen gelesen hatten, warnte vor dem bitteren Leid einer ,abgöttischen Liebe' ${ }^{45}$

Wenn Abaelard sich als Theologe über Heloisas ,götzendienerischen Gefühle' Rechenschaft ablegte, kam er zu einem noch kritischeren Ergebnis: Die Art, wie Heloisa ihre absolute Liebe beschrieben hatte, gemahnte an die Beziehung zum höchsten himmlischen Wesen: Theologen definieren die Sünde als eine Beleidigung Gottes; Heloisa hatte erklärtermaßen stets Abaelards Willen erfüllt, um ihm eine solche Beleidigung (offensio) zu ersparen (vgl. Anm.37). Ihr absolutes Vertrauen, den besten Mann zu lieben $^{46}$, widersprach nicht nur Abaelards Selbstbild, es hatte eine fatale Ähnlichkeit mit der christlichen Glaubensgewißheit. Der Gegenstand von Heloisas Hoffnung war Abaelards gratia (vgl. Anm.38); in der Theologie wird unter gratia der Inbegriff göttlichen Wohlwollens und Gnade verstanden. In erster Linie bekümmerte sich Heloisa um Abaelards Ehre und Freiheit (vgl. S.5 und 12); auch dies erinnerte an Debatten der Gottesgelehrten de maiore Dei gloria und Spekulationen über die Unergründlichkeit des göttlichen Willens. Auch als sie ihn schließlich gebeten hatte, ihr Herzenskündiger zu sein (vgl. S.12), rückte sie ihn an die Stelle Gottes, den Prüfer von Herz und Nieren. - Mußte sich Abaelard als Auslöser und Adressat all dieser Gefühle nicht überfordert fühlen?

Ein zweiter Grund, weshalb Abaelard so unzureichend auf Heloisas Freundschaftsbegehren reagierte, mag darin gründen, daß er sich aufgrund seiner ehemaligen Liebesleidenschaft ,blockiert'

${ }^{45}$ LUKREZ: De rerum natura IV, 1052-1148: Der Schüler Epikurs beschreibt die auf eine einzige Person fixierte Liebe als ein Geschwür (ulcus), bei dem eisige Sorge (frigida cura) die Hitze ablöse, das Verlangen ungestillt und die Befriedigung trügerisch bleibe; daher wiederholt er: "Da ist alles eitel” (nequiquam).

${ }^{46}$ Vgl. den rhetorischen Analogieschluß der Philosophin Aspasia (aus: [Pseudo]CICERO: De inventione I.31,51f.), wonach jemand im Gatten den besten Mann bzw. die beste Frau liebe. Heloisa fährt fort, ihre Liebe gründe sich auf diese absolute Gewißheit, vgl. Brief 2, ed. MUCKLE S.71, ed. BROST S.82, ed. KRAUTZ S.65 und ed. RADICE S.114f. 
fühlte. Die radikal abwertende und schuldbewußte Weise, in der Abaelard in Brief 5 seine Liebesleidenschaft schilderte, wirkt geradezu, selbstzerfleischend'.

Unumwunden bejahte Abaelard den von Heloisa in Brief 2 geäußerten "Argwohn aller" (vgl.S.12), wonach ihn eher geschlechtliche Begierde als Freundschaft, die Glut sinnlicher Leidenschaft statt echte Liebe zu Heloisa getrieben habe. ${ }^{47}$ Neben dem an Heloisas Onkel begangenen "Verrat" und „Verbrechen” klagt sich Abaelard an, Heloisa gegen ihren Willen und ihre Bitten gedrängt, ja die in ihrer Selbstbeherrschung stärkere, aber in ihrer weiblichen Schwäche unterlegene sogar mit Drohungen und Gewalt gefügig gemacht zu haben. ${ }^{48}$

Er gedenkt seines alten Adam als eines furchtbar getriebenen, durch den Zwang seiner Sexualität ${ }^{49}$ unfreien Mannes, nicht fähig,

${ }^{47}$ Amor meus, qui utrumque nostrum peccatis involvebat, concupiscentia, non amor dicendus est. Miseras in te meas volptates implebam, et hoc erat totum quod amabam. Vgl. dieses Zitat aus: ed. MUCKLE S.92 mit S.72; ed. BROST S.140 mit S.84; ed. KRAUTZ S.110f. mit S.67; ed. RADICE S.153 mit S.116. Das Spektrum seiner Schilderung reicht von Ungezügeltheit über schändliche Buhlerei bis zu schamlosen Beschmutzungen und dem Ausleben elendiglicher Lüste. Vgl. ed. MUCKLE S.88f.: intemperatia meae libidinis; flagitium; impudentissimae pollationes; contaminatio; quantae turpitudines; immoderata mea libido; tantus concupiscentiae ardor; obscenissimae et miserrimae voluptetes; spurcititia; contagia carnalium pollutionum; sordida et vilia. Vgl. ed. BROST S.130-133, ed. KRAUTZ S.102-105 und ed. RADICE S.146-148.

${ }^{48}$ Ed. MUCKLE S.89: Sed et te nolentem et, prout poteras, reluctantem et dissuadentem, quae natura infirmior eras, saepius minis ac flagellis ad consensum trahebam; S.92: Quo enim naturaliter sexu infirmior eras et fortior continentia, poenae minus eras obnoxia. Ed. BROST S.132 und 141; ed. KRAUTZ S.104 und 112; ed. RADICE S.147 und 154 .

${ }^{49}$ Ed. MUCKLE S.92: invitus, non amore tui, sed coactione mei; ed. BROST S.140 und ed. KRAUTZ S.111 beziehen die Stelle irrtümlich auf die an Abaelard verübte ,Gewalttat' der Kastration; ed. Radice S.153 „under compulsion”. Weitere Textstellen zu Abaelards Unfreiheit: Ed. MUCKLE S.89: concupiscentiae iugum "das Joch heftiger Begierde"; ed. Muckle S.93: aestus huius concupiscentiae, in qua una totus per immoderatam incontinentiam occupatus eram "die Glut der Begierde, von (in) der ich gänzlich durch eine maßlose Unenthaltsamkeit beansprucht (gefangen) war". Ed. KRAUTZ S.105 und 112 und ed. RADICE S.148 und 154 deutlicher als ed. BROST S.133 und 142. 
enthaltsam zu leben, und durch die Glut seiner Gier an seine Geliebte gefesselt. Solch armseliges, der Welt verfallenes Leben gleiche dem des Viehs; Abaelard zitiert den Propheten Joel (Vulgata: 1,17a): „Und es verfaulte das Vieh in seinem Mist.”

Aus der Warte eines derart negativen Rückblicks und der darin dominierenden Schuldgefühle mußte ihm Heloisas (erotisch ziemlich aufgeladenes) Freundschaftsbegehren in einem ambivalenten Licht erscheinen. Darf deshalb angesichts dieser ,psychischen Kausalität' offen bleiben, ob Abaelard Heloisas Freundschaftsbegehren überhaupt wahrnahm oder ob er es bewußt ignorierte und abwehrte?

Meines Erachtens gibt es sowohl literarische als faktische Gründe, die es nicht geraten erscheinen lassen, Abaelards Rückblick so stehen zu lassen. Denn in der zweiten Hälfte von Brief 5 lieferte Abaelard seiner Korrespondentin, die um vergangene Erweise von gratia und um neu erhoffte Zeichen seiner Erkenntlichkeit und Freundschaft kreiste (vgl. S.10, Anm.38 und S.12f.), das ,theologische Gegenstück' zum Thema: Vor dem in grellsten Farben gemalten Bild eigener Erlösungsbedürftigkeit und Sünde wollte er die heilende Kraft göttlicher Gnade (gratia) in umso strahlenderes Licht rücken. Umrahmt von Ps 40,18: „Der Herr sorgte sich um meinetwillen", bezeugt Abaelard, wie ihn im Unterschied zu Paulus (der seinen „Pfahl im Fleisch”, seine Epilepsie, nicht los wurde) und Origenes (der Hand an sich gelegt und sich selbst entmannt haben soll) die göttliche Gnade von dem Organ befreite, in welchem seine Gier ${ }^{50}$ ihren Ursprung gehabt habe, um so seine Seele zu retten.

${ }^{50}$ Abaelards Auffassung würde verkürzt, wollte man ihm schlicht Sexualitätsfeindlichkeit oder Haß auf den eigenen Leib vorwerfen. Der springende Punkt ist ein verantwortlicher Gebrauch der natürlichen Triebe. So schreibt er in seiner Klosterregel analog über die Nahrung: „Es ist nicht die Speise als solche, sondern die maßlose Gier (appetitus) das Sündhafte [...] Auch der alte Feind [der Teufel] wußte es, daß nicht die Speise an und für sich, sondern die Gier (concupiscentia) nach der Speise der Verdammung Ursache ist [...]", zitiert Brief 8, ed. BROST S.331. Ed. MUCKLE S.278; ed. KRAUTZ S.272f. und ed. RADICE S.244. 
Möge nun auch seine unzertrennliche Gefährtin, in geringerem Maß der Schuld und der Gnade teilhaftig als er selbst, in seinen Dank (gratia) einstimmen: In der Welt hätte sie die niedrigen Pflichten einer Ehefrau verrichtet und wenige Kinder für die Welt geboren. Mit ihrer Klugheit bringe sie jetzt aber zahlreiche geistliche Töchter hervor und widme sich dem Studium der Heiligen Schrift.

Er fährt fort: Ihr wahrer Freund, Christus, begehre sie um ihretwillen, nicht wegen des Ihren (vgl. S.10). Mit seinem Selbst, seinem Leben und Blut, kaufte er sie frei und errettete ihre Seele. Aus freiem Willen habe Christus für sie gelitten, während er bloß durch sie gegen seinen Willen und aus eigenem Zwang gelitten und ihre Seele dadurch zur Verzweiflung gebracht habe.

Abaelard überhörte also keineswegs Heloisas Freundschaftsbegehren ${ }^{51}$, ohne es doch angemessen beantworten zu können; deshalb versuchte er es in die damalige „Brautmystik” umzulenken, mit wenig Aussicht auf Erfolg. Denn aus ihren XLII Problemata zu urteilen, konnte Heloisa mit dergleichen Allegorien wenig anfangen; ihre exegetischen Anfragen richten sich stets realitätsbezogen und nüchtern auf den geschichtlichen und moralischen Bibelsinn.

Brief 6 hat eine Grußformel, deren Erklärung in der Literatur enormen Scharfsinn mobilisierte. Sie lautet: Suo specialiter, sua singulariter. Abaelard hatte in Brief 3 noch geschrieben: „Gedenke daher in Deinen Gebeten immer dessen, der in einem vorzüglichen Sinn der Deinige ist" (Memento itaque semper in orationibus tuis eius qui specialiter est tuus) und damit sich selbst gemeint. Im Gegenzug zu ihrer Argumentation, wonach sie auch in ihrer Seele ganz ihm gehören wollte (vgl. S.10), setzte er ihr im Brief 5 die heilige Vorbedeutung ihres Namens auseinander: Sie sei das Eigentum Gottes, da „Heloisa” sich vom Gottesnamen Elohim herleite. Ferner wies er sie an Christus

${ }^{51}$ So schrieb er gegen Ende von Brief 5, daß er sich Heloisa "mehr in geistiger Liebe zugetan, als in Furcht und Zittern untertan" fühle, zitiert ed. BROST S.143; ed. KRAUTZ S.113 und ed. RADICE S.154. Vgl. ed. MUCKLE S.93: Et nunc [...] me habes servum quem olim agnoscebas dominum, magis tibi tamen amore nunc spirituali coniunctum quam timore subiectum. 
als „ihren wahren Freund”, der allein ihre Hingebung, ihr Mitleiden und ihre Zerknirschung verdiente, nicht er. ${ }^{52}$

Während ihre Grußformel in Brief 4 noch fromm und ergeben lautete: Unico suo post Christum, unica sua in Christo („Ihrem Einzigen nach Christus, seine Einzige in Christus"), replizierte sie auf Abaelards Empfehlung von Christus als ihrem wahren Freund unbeeindruckt und kritisch, indem sie auf die ehemalige Zusage Abaelards in Brief 3 rekurrierte: "Dem im wahrsten Sinne des Wortes Ihrigen, die in einzigartiger Weise Seine" und ließ Christus bewußt beiseite. An dieser Grußformel ist nichts kryptisch: Sie ist ein Signal der Abgrenzung gegen Abaelards Ansinnen und zuletzt ein Beleg dafür, daß Heloisa vor ihrem „Seelsorger" Abaelard kapituliert (vgl. S.2) hätte!

Wenn es nun andererseits um die Realität von Abaelards Empfinden für Heloisa geht, dürfen wir im Interesse der Wahrheit seinem finsteren und schuldbeladenen Rückblick wohl auch ein Stück weit widersprechen ${ }^{53}$ : Denn erstens führte die literarische Einbindung dieses Rückblicks in den Gnaden-Topos zu einer hyperbolischen Darstellung, die sich zweitens durch den helleren Bericht in der Autobiographie relativiert. ${ }^{54}$ Drittens spricht für eine vom kommentierten Rückblick abweichende Empfindungsrealität das durch Roscelin beglaubigte persönliche Wappen Abaelards, das die verbundenen Häupter einer Frau und eines Mannes abbildete. ${ }^{55}$

${ }^{52}$ In hoc, obsecro, non in me tua tota sit devotio, tota compassio, tota compunctio, ed. MUCKLE S.92; ed. BROST S.140; ed. KRAUTZ S.111; ed. RADICE S.153.

${ }^{53}$ Heloisa schrieb in Brief 2, daß sie etwas Linderung für ihren Schmerz fände, wenn angesichts des schrecklichen Verdachts aller Welt (vgl. S.12 und 14) Abaelards Liebe für sie einige Fürsprecher fände, um sie zu rechtfertigen (aliquos in excusationem sui amor tuus inveniret), vgl. ed. MUCKLE S.72, ed. BROST S.84, ed. KRAUTZ S.67 und ed. RADICE S.116.

${ }^{54}$ Vgl. oben S.4 respektive H.C., ed. MONFRIN S.72f., ed. BROST S.21, ed. KRAUTZ S.16 und ed. RADICE S.67f.

${ }^{55}$ Sein Jugendlehrer ROSCELIN schickte ihm um 1120 (nach Abaelards Verstümmelung, auf die er beleidigend eingeht) die Epist.XV, ed. J. REINERS, Beiträge VIII,5, Münster 1910. S.80, 19-24: Unde quis dubitat, quanto adhuc in eam ardeat amore, qui tali eam capitum coniunctione non erubuit honorare? "Wer möchte bezweifeln, daß er sie weiterhin leidenschaftlich liebt, da er sich nicht schämt, sie [in besagtem persönlichem Wappen] durch eine solche Verbindung zweier Häupter zu ehren." 
Wie auch mit seiner Grabinschrift ${ }^{56}$ bekundete Abaelard mit dem besagten Siegel vor aller Welt seine das Liebesdrama überdauernde Verbundenheit mit Heloisa.

Ein dritter und letzter Grund für Abaelards Unverständnis läßt sich an der zeitgenössischen Spiritualität festmachen. Das zwölfte Jahrhundert wurde im Anschluß an die beiden Werke des Aelred von Rievaulx, dem Speculum caritatis aus den vierziger Jahren und De spiritali amicitia aus den frühen sechziger Jahren, das Zeitalter der amicitia. Allerdings ist sofort einzuschränken: Die Mehrzahl der Opera über spirituelle Freundschaft richtete sich an Mönche, also an Männer auf dem Weg zu ihrer geistlichen Vervollkommnung.

Das Thema blieb für Nonnen lange Zeit ein Tabu. Denn Frauen nahm man nicht als Wesen wahr, die individuell und kollektiv im Kloster um ihre geistliche Vollkommenheit rangen. Nonnen galten per se aufgrund ihrer Keuschheit als heilig ${ }^{57}$; ihre Heiligkeit war lediglich ein mit Gottes Hilfe zu bewahrendes Attribut. In Freundschaften sah man eher eine Gefahr für die so verstandene weibliche Heiligkeit als eine Hilfe für ein gottgefälliges Leben.

${ }^{56}$ Vgl. NIGGLI, in: Peter Abaelard 2003 (Anm.8), S.324f. und 405.

${ }^{57}$ Vgl. BARBARA NEWMAN: "Flaws in the Golden Bowl: Gender and Spiritual Formation in the Twelfth Century", in: Traditio 45, 1990, 111-146; Zitat S.123: "The perception of virginity as the quintessence of female holiness naturally had momentous consequences for the spiritual life, and advice on preserving this state dominates the women's literature of formation." Die physische Jungfräulichkeit galt als eine von Gott bewahrte, quasi-magische Eigenschaft. Wenn z.B. Aelred die Reinheit seiner Schwester mit seiner eigenen kontrastiert, hebt er bei ihr lediglich den Status und das Sein, nicht ihren existentiellen Einsatz hervor. Das Fleisch einer Jungfrau vergleicht er mit einem irdenen Gefäß, in welchem Gold aufbewahrt wird; zerbricht das Gefäß, ist das Gold verschüttet, vgl. AELRED VON RIEVAULX: De institutione inclusarum 14 und 32, in: Opera omnia, ed. A. HOSTE et C.H.TALBOT, CCCM 1, Turnhout 1971, S.650 Z 475f., und S.674. Dergestalt wurde das Ringen der Nonnen um ihre geistliche Vollkommenheit verkannt. Unter dem Eindruck von Heloisas Aufruhr - ohne schon wie AELRED die Bedeutung der Freundschaft für den Weg mit Gott zu ahnen - verstand ABAELARD die Nonnen dagegen als ,Soldatinnen' im Kampf gegen den Teufel und die mit Verständnis gelesen Heilige Schrift als ihre ,Rüstung', vgl. Brief 8, ed. McLAUGHLIN S.250 und 287, ed. BROST S.264 und 352f., ed. KRAUTZ S.213 und 291 und ed. RADICE S.196f. und 260. 
Im damaligen Nonnenalltag gab es kaum Freundschaften; die Freundschaft zwischen einer Nonne und einem Mönch hätte sich in der geschlechtergetrennten Abgeschiedenheit ihrer Klöster ohnehin nur auf dem Korrespondenzweg verwirklichen lassen. Der rege Briefwechsel, den z.B. Anselm von Canterbury bereits im elften Jahrhundert mit Frauen unterhielt, richtete sich nicht an sie als Individuen; seine ,Modellbriefe' waren an sie als Repräsentantinnen bestimmter gesellschaftlicher Funktionen wie die Mutter, die Schwester, die Klosterfrau oder die Aristokratin adressiert. ${ }^{58}$

Mit ihrem dringenden Freundschaftsbegehren war Heloisa ihrer Zeit in gleicher Weise voraus wie mit ihren humanistisch aufgeschlossenen Überlegungen zum Nonnenstand und zu einer gemäßigten, auf die Erfordernisse von Frauen eingehenden Klosterregel $^{59}$; sie konnte es sich in ihrer Kühnheit z.B. problemlos vorstellen, als Äbtissin allein mit männlichen Gästen zu speisen.$^{60}$ Ihrer energischen Anfrage in Brief 6, die Benedikts Regel (die in Klöstern unterschiedlicher Denomination die verbindliche Regel war) als geschichtlich bedingt anstatt als überzeitliches Dokument auffaßte, ist es zu verdanken, daß Abaelard über innovative Wege der Kooperation zwischen den Geschlechtern unter Klosterbedingungen nachdachte. Dabei mußte ihm daran liegen, die in Fontevrault bereits unter Petronilla von Chemillé, der Nachfolgerin von Heloisas Mutter Hersendis, zu Tage getretenen und durch den Doppelklostercharakter bedingten Mißstände zu vermeiden. ${ }^{61}$

Das (unverwirklicht gebliebene) Doppelklostermodell Abaelardscher Prägung ${ }^{62}$ legte die schwere körperliche Arbeit und

${ }^{58}$ Vgl. SALLY N. VAUGHN: Saint Anselm and the Handmaiden of God. A Study of Anselm's Correspondence with Women, Utrecht Studies in Medieval Literacy Bd.7, Turnhout 2002.

${ }^{59}$ Vgl. U. NIGGLI, in: Peter Abaelard 2003 (Anm.8), S.101-108.

${ }^{60}$ Brief6, ed. MUCKLES.242; ed. BROST S.151, ed. KRAUTZS.117 und ed. RADICE S.160.

${ }^{61}$ Vgl. W. ROBL, in: Peter Abaelard 2003 (Anm.8), S.50 und S.85 die Anm.231.

${ }^{62}$ Er entwickelte seine Ideen zum Doppelkloster in einem längeren Exkurs, nachdem er die Anforderungen an eine Äbtissin bzw. Diakonin dargelegt hatte, vgl. Brief 8, ed. McLAUGHLIN S.258ff., ed. BROST S.282-288, ed. KRAUTZ S.229234 und ed. RADICE S.209-214. 
alle außerhalb des Klosterareals zu verrichtenden Besorgungen in die Hände einer mit dem Frauenkloster lose verbundenen, aber für sich lebenden klösterlichen Männergemeinschaft. Trotz der grundsätzlichen Aufgeschlossenheit für eine Kooperation zwischen den Geschlechtern unterband sein Modell jedoch jeden persönlichen, geschweige denn freundschaftlichen Kontakt zwischen den Nonnen und den Mönchen. ${ }^{63}$

So wie Abaelard sich die Beziehung zwischen dem Abt des Männerklosters und der Äbtissin des zugehörigen, aber klar untergeordneten Frauenklosters ${ }^{64}$ im Paraklet vorgestellt hatte, hätte wohl nur er selber den Posten jenes stets dienenden und jeden berechtigten Wunsch sofort erfüllenden, aber niemals befehlenden und unberechtigte Anliegen stillschweigend übergehenden praepositus ausfüllen können. Denn obwohl diese Vorgaben einen vertrauten Umgang miteinander und ein tiefes Verstehen voraussetzen, verlangte die Regel paradoxerweise zwischen dem Abt und der Äbtissin eine distanzierte Beziehung; bei ihren häufigen Zusammenkünften und Besprechungen hätte z.B. stets eine dritte Person anwesend sein müssen. Die gewöhnlichen Mönche wären ohnehin durch ein spezielles, vor der Äbtissin abzuleistendes

${ }^{63} \mathrm{Vgl}$. Brief 8, ed. McLAUGHLIN S.260: Nullus igitur virorum nisi licentia praepositi ad sorores accessum habebit [...]. Nulla umquam sororum septa [das ist die Einfriedung bzw. der Bereich der Nonnen] monasterii egredietur [...]. Nullus umquam fratrum septa haec ingredietur [...]. Si quis forte contra hoc praesumpserit absque dilatione de monasterio projiciatur. S.261 Mitte: Sogar die Priester gesetzteren Alters, die einer Sterbenden die letzte Ölung spenden, sollen durch einen Bettschirm (interposito pariete) vor der Versammlung der Schwestern verborgen gehalten werden. S.267: Quorum [gemeint sind der bei wöchentlichem Turnus die Messe abhaltende Mönch und seine Gehilfen] accessus vel recessus ita fiant ut sororum conventui nullatenus pateant. Nach der Messe teilt ein bejahrter Priester mindestens drei Mal im Jahr den Nonnen (die drei Tage vorher beichteten) die Kommunion aus, aber seine Gehilfen haben vorher die Kirche zu verlassen propter tollendam tentationis occasionem. Vgl. ed. BROST S.287f., 291 und 305; ed. KRAUTZ S.234, 237 und 249f.; ed. RADICE S.213, 216 und 226.

${ }^{64} \mathrm{Vgl}$. Brief 8, ed. McLAUGHLIN S.259 Abs.2: monasteria feminarum monasteriis virorum ita semper esse subjecta volumus [...]. Ed. BROST S.285, ed. KRAUTZ S.232 und ed. RADICE S.212. 
Gelübde von den Nonnen ferngehalten worden. Kurzum: In Abaelards idealem Doppelkloster war kein Schimmer einer geistlichen Freundschaft zwischen den Geschlechtern vorgesehen!

Im Eingehen auf den Briefwechsel zeigte sich: Heloisa war keineswegs bloß eine sich nach ihrem ehemaligen Liebhaber glutvoll verzehrende junge Frau, als die sie ,cum grano salis' in die Legende und Literatur über Jahrhunderte eingegangen ist. Um eine andere, auch in Bezug auf ihre Gefühle autonom denkende Heloisa zu entdecken, erwies es sich als unnötig, ihre Briefe oder auch nur einzelne Passagen darin einer fremden Hand zuzuschreiben, und etwa wie Muckle und Benton (vgl.die Anm.4f.) zu behaupten, ein genialer Fälscher oder Abaelard selbst habe das der männlichen Anleitung bedürftige, weil sonst seinen Gefühlen hilflos ausgelieferte anschmiegsame Naturell des weiblichen Wesens vorführen wollen. ${ }^{65}$ In derartigen, meist in frauenfeindlicherem Vokabular ausgedrückten Konstruktionen ist die persönliche Spannweite dieser hoch begabten Frau verkannt worden.

Statt beglaubigter Fakten ist uns aus Abaelards letztem Lebensjahrzehnt vor allem Literatur erhalten: Der bereits kränkelnde Abaelard vollendete nicht nur herausragende scholastische Schriften wie seine Ethik, den Römerbriefkommentar und die letzte Fassung seiner Theologie, sondern verfaßte für die Äbtissin des Paraklet auch liturgische und exegetische Werke, die sog. Parakletschriften. ${ }^{66}$ In ihnen erreichte er als Mensch, Ethiker und geistlicher Theologe einen Rang, zu dem Heloisas Überlegungen und ihre Freundschaft nicht unwesentlich beitrugen.

${ }^{65}$ In der längeren Fassung des vorliegenden Artikels (vgl. Anm.8) gehe ich auch auf die sog. "impassioned and carnal outbursts” Heloisas (vgl. MUCKLE in Anm. 4) ein, die in der Sekundärliteratur breit verhandelt wurden.

${ }^{66}$ Ihre eigenen Vorgaben klug erläuternd, bat ihn Heloisa in Brief 6 nicht nur um Aufklärung zur Herkunft (unde) und zum Vorbild (auctoritas) des Nonnenstandes und um eine Klosterregel für Benediktinerinnen (ut aliquam nobis regulam instituas, ed. MUCKLE S.242), die er in Brief 7 und 8 (einschließlich Brief 9) erfüllte. Auf ihr Ersuchen sandte er ihr auch Hymnen, Sequenzen, Predigten und eine Auslegung des göttlichen Sechstagewerks (Hexaemeron) und beantwortete ihre 42 bibeltheologischen Fragen (Problemata Heloissae).

Educ. e Filos., Uberlândia, v. 20, n. 40, p. 173-206, jul./dez. 2006. 
Im Gegenzug erlangte Heloisa ihre volle Statur als Ordensmutter und Klostergründerin erst nach Abaelards Tod im April 1142, erbrachte ihre Lebensleistung also weithin unabhängig von Abaelard. ${ }^{67}$ Zwischen 1142 und 1163 (sie starb im Mai 1164) gründete sie sechs Tochterklöster und gab dem Mutterkloster Paraklet und seinen Filiationen in ihren Institutiones nostrae ein eigenes, cachet'. In dem wahrscheinlich um 1150 von ihr redigierten Briefwechsel mit Abaelard sollte die Nachwelt nebst Abaelards Klosterregel in Brief 8 Nachrichten zum Gründerpaar des Paraklet erhalten ${ }^{68}$, der de facto ein reines Frauenkloster blieb. Gemäß dem Ethos des Paars enthielten diese Nachrichten nicht nur lebensgeschichtliche Fakten, sondern in der Hauptsache das exemplarische und aufrichtige Ringen beider je für sich und miteinander auf ihrem Weg zu Gott.

Solange Abaelard lebte, füllte Heloisa für ihn die klassische Rolle einer Muse und Anregerin aus und stand zumindest in geistigem Austausch mit ihm. Danach kehrte die autonom Denkende alles vor, um seine Gründung zu erweitern und die Erinnerung an ihn zu pflegen; auch das war ein Ausdruck ihrer Freundschaft.

${ }^{67} \mathrm{Vgl}$. das Kap.7 in der längeren Fassung des vorliegenden Artikels (Anm.8).

${ }^{68}$ Vgl. JACQUES MONFRIN: "Le problème de l'authenticité de la correspondence d'Abélard et d'Héloïse" [vorgetragen in Cluny 1972], jetzt auch in: Études de philologie romane, Genf 2001, S.301-316. 